Ensino, Saúde e Ambiente-V11 (1), pp.125-136, Abril. 2018

\title{
UMA ANÁLISE DOS ENUNCIADOS DE ARTIGOS SOBRE RECURSOS AUDIOVISUAIS EM REVISTAS DE DIVULGAÇÃO CIENTÍFICA: UM APORTE PARA O ENSINO DE CIÊNCIAS
}

\section{AN ANALYSIS OF THE STATEMENTS OF ARTICLES ABOUT AUDIOVISUAL RESOURCES IN SCIENTIFIC DIVULGATION JOURNALS: A CONTRIBUTION TO SCIENCE EDUCATION}

\author{
Nilza Dias Silva ${ }^{1}$, Marcus Vinicius Pereira ${ }^{2}$, Maria Cristina do Amaral Moreira ${ }^{3}$ \\ ${ }^{1}$ Instituto Federal do Rio de Janeiro, nilgab2003@yahoo.com.br \\ ${ }^{2}$ Instituto Federal do Rio de Janeiro, marcus.pereira@ifrj.edu.br \\ ${ }^{3}$ Instituto Federal do Rio de Janeiro, maria.amaral@ifrj.edu.br
}

\begin{abstract}
RESUMO
Os recursos audiovisuais compreendem ferramentas que possibilitam compartilhamento e acesso diversificado, podendo, assim, se constituir como suportes pedagógicos de amplo alcance na escola e no ensino de ciências. Neste trabalho fazemos uma análise de artigos de divulgação científica em periódicos sobre a temática dos recursos audiovisuais. Foram analisados os artigos da Revista de Manguinhos e Ciência Hoje a partir do enquadre teórico de Bakhtin e dos conceitos de enunciação e dialogismo distribuídos em quatro categorias: assunto, justificativa, problematização e ausências. Como resultado, inferimos que, nas representações discursivas dos artigos, a vinculação de recursos audiovisuais com a divulgação científica se dá ainda de forma ambígua e difusa. Diferentes concepções sobre essa vinculação foram encontradas, o que mostra que não há nem um consenso no discurso, nem uma homogeneidade na maneira como tais recursos são tratados, já que há variação na consideração deles como uma ferramenta de informação ou um artefato tecnológico de uso comum que se torna objeto de "curiosidade científica".
\end{abstract}

Palavras-chave: linguagem, dialogismo, enunciado, recursos audiovisuais, divulgação científica.

\begin{abstract}
Audiovisual resources include tools that enable sharing and diversified access. Thus they constitute broad-based pedagogical supports in school and in science education. In this work we make an analysis of scientific divulgation articles on the topic of audiovisual resources. Articles from Revista de Manguinhos and Ciência Hoje journals were analyzed according to Bakhtin's theoretical framework and the enunciation and dialogism concepts within four categories: subject, justification, problematization and absences. As a result, we infer that in the discursive representations of the articles the linkage of audiovisual resources with the scientific divulgation still occurs in an ambiguous and diffuse way. Different conceptions of this linkage have been found, which shows that there is neither a consensus in the discourse nor homogeneity in the way in which these resources are treated, since this treatment varies in their consideration as an information tool or a commonly used technological artifact which becomes the object of "scientific curiosity".
\end{abstract}

Keywords: language, dialogism, enunciation, audiovisual resources, scientific divulgation. 


\section{INTRODUÇÃO}

O uso de recursos audiovisuais em sala de aula tem sido frequente no ensino de várias disciplinas. Historicamente, os recursos audiovisuais "compõem uma gama de materiais que podem e devem ser utilizados em salas de aula pelos professores" (SANTOS e ARROIO, 2009, p. 2), e que, em geral, têm contribuído especificamente para ilustrar, exemplificar e introduzir conhecimentos de um tema a ser ensinado. Arroio e Giordan (2006) consideram o vídeo como um suporte pedagógico não convencional que tem um papel para além da motivação às aulas, por reunir características tais como som, imagem e ação, contribuindo para reflexão de ideias e construção do conhecimento do aluno, aspectos alcançáveis mediante um apropriado plano de aula. A temática dos vídeos tem relação com as inúmeras possibilidades que esse recurso traz pelo seu formato eletrônico com a transmissão por intermédio de instrumentos sem/com a internet, constituindo uma ferramenta de amplo compartilhamento e de fácil acesso. Na sociedade da informação e comunicação, com o alargamento da banda de acesso à internet e o aumento do número de pessoas conectadas via celulares e computadores, o vídeo se tornou ainda mais popular, sobretudo com as redes sociais.

Assim como um vídeo pode ser considerado didático, revistas de divulgação científica (RDC) também são recursos pedagógicos para professores e alunos, uma vez que podem ser compreendidas como materiais educativos, estimulando o contato dos alunos com os diversos tipos de textos, ampliando as formas de obtenção de informações, contribuindo com questões novas/atuais, contextualizando o conhecimento científico, entre outras possibilidades (MARTINS, NASCIMENTO e ABREU, 2004; FERREIRA e QUEIROZ, 2012).

Neste trabalho, temos como interesse entender a relação entre os recursos audiovisuais (RAV) e a divulgação científica (DC). Dentre os RAV disponíveis atualmente, compreendemos que os vídeos têm sido cada vez mais protagonistas para a DC, e as RDC desempenhado um papel de divulgadoras de artigos sobre vídeos de conteúdo científico. Nesse sentido, eles se constituem como relevante veículo de potencial pedagógico para sala de aula, podendo estimular professores em suas aulas a fim de comunicar melhor a ciência no espaço escolar, bem como colaborar na reflexão sobre as melhores estratégias para construir um discurso científico mais dialógico.

A perspectiva teórica que nos apoiamos é a interacional de Bakhtin (2003), na qual a interação é sempre polifônica, ou seja, engloba um conjunto de vozes 
(antecipando e retomando), sob uma visão dialógica da linguagem. Portanto, esse estudo teve como foco investigar os enunciados presentes em artigos sobre vídeos em RDC por meio do entendimento da cadeia dialógica dos textos presentes nos enunciados, ao valorizar-se não só o conteúdo explícito em cada enunciado, mas, em particular, as subjetividades socio-históricas entrelaçadas nas produções discursivas/textuais que comunicam o conhecimento científico aos mais diversos públicos. Tomamos o conceito de linguagem como um produto social e histórico segundo a abordagem socio-interacionista de Vygotsky (2002) e, sendo assim, a análise será feita por abordagens que acometam, além do aspecto sistemático da língua, a observação do funcionamento social, histórico e cognitivo de tais produções.

\section{MARCO TEÓRICO}

Um conceito chave para Bakthin é o caráter dialógico da linguagem, ao considerá-la sempre como interativa em uma relação que compreende alternância de vozes (BRAIT, 2006). Segundo Bakhtin (2003), todo enunciado faz parte de uma interação social, ou seja, toda fala ${ }^{1}$, ainda que pareça individual, serve a uma ação comunicativa, por isso a língua é considerada uma prática enunciativa.

A enunciação enquanto tal é um puro produto da interação social, quer se trate de um ato de fala determinado pela situação imediata ou pelo contexto mais amplo que constitui o conjunto de condições de vida de uma determinada comunidade linguística. (BAKHTIN, 2003, p. 7)

Para Bakthin (2003, p. 275), “o enunciado não é uma unidade convencional, mas uma unidade real" na qual os falantes se alternam. Nesse sentido, um enunciado não é o mesmo que uma frase, parágrafo ou texto, pois esse transcende essa ordem estrutural. Enunciados repetidos, reativados em novos contextos, podem representar aspectos diferentes para um mesmo debate. Cardoso (2005, p. 37) esclarece que "um enunciado suporta enunciações distintas, dado que tem uma existência material e sua materialidade é repetível", sendo essa materialidade dos enunciados dada por uma ordem institucional. Já Marchezan (2006, p. 117) considera que:

Diálogo e enunciado são assim dois conceitos interdependentes. O enunciado de um sujeito apresenta-se de maneira acabada permitindo/provocando, como resposta, o enunciado do outro; a réplica, no entanto, é apenas relativamente acabada, parte que é de uma temporalidade mais extensa, de um diálogo social mais amplo e dinâmico.

\footnotetext{
1 "Toda compreensão da fala viva, do enunciado vivo é de natureza ativamente responsiva [...] compreensão passiva do significado do discurso ouvido é apenas um momento abstrato da compreensão ativamente responsiva real e plena, que se atualiza na subsequente resposta em voz real alta" (BAKHTIN, 2003, p. 271).
} 
O dialogismo, nesse estudo, é entendido como um princípio da teoria bakhtiniana, a qual não estabelece limitação e redução de sentidos, uma vez que busca ressonâncias nos discursos que se repetem (ditos e já-tidos) e de que maneira se repetem, assim como aqueles que quase nunca aparecem (não-tidos). (DI FANTI, 2003).

Em se tratando da DC, Orlandi (2008, p. 149) a considera como uma forma de discurso da ciência com um "percurso na sociedade e na história", que publica e apresenta o saber científico de forma particular. Para essa autora, entretanto, o discurso da DC não é uma versão do texto científico, uma vez que, em geral, acentua o "aspecto técnico-científico do discurso" (ORLANDI, 2008, p. 157). A informação científica do texto de DC apresenta terminologia para dar credibilidade à questão científica, como destaca Orlandi (2008, p. 161) ao considerar o

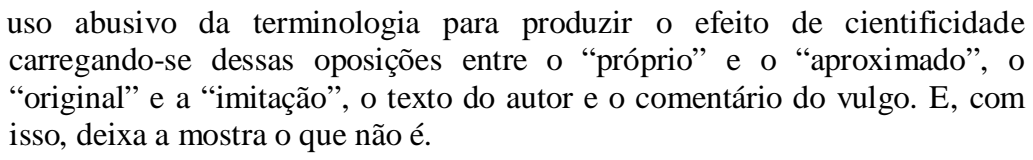

Essa forma de representar o conhecimento de forma aproximada, na valorização da terminologia, tem também encontrado espaço na escola - uma convergência entre a didatização do conhecimento e a DC. Nesse sentido, os textos selecionados na análise que apresentamos são entendidos como constituídos de enunciados que pressupõem outros em rede, uma vez que se inserem em uma prática social em comum - a da DC.

\section{METODOLOGIA}

O corpus da pesquisa é constituído de duas revistas que têm seu conteúdo voltado para a DC - Revista de Manguinhos e Ciência Hoje - que possuem como objetivo a investigação e a disseminação de resultados de pesquisas na área de ciências. Elas se distinguem de outros periódicos pelo seu público-alvo e, por conseguinte, a natureza dos textos produzidos.

A Revista de Manguinhos surgiu a partir da Folha de Manguinhos como veículo oficial da Fundação Oswaldo Cruz (FIOCRUZ) aos poderes legislativo e executivo, a instituições de ciência e tecnologia e a órgãos de saúde de todo o país.

A pauta reúne os acontecimentos importantes da instituição e do país nas áreas em que a Fiocruz se faz presente: saúde, ciência, tecnologia e ensino. Publicação plural, reflete as iniciativas, programas e projetos da Fundação em reportagens e textos que mostram, de maneira abrangente, a atuação nacional (e também internacional) da Fiocruz. ${ }^{2}$

\footnotetext{
${ }^{2}$ Disponível em: <https://portal.fiocruz.br/pt-br/content/revista-de-manguinhos〉.
} 
Já a Ciência Hoje existe desde 1982 e foi criada no âmbito da Sociedade Brasileira para o Progresso da Ciência (SBPC), importante sociedade científica fundada em 1948, integrando hoje uma das publicações do Instituto Ciência Hoje (ICH), que também publica a revista Ciência Hoje das Crianças, uma coleção de livros paradidáticos intitulados Ciência Hoje na Escola, além de livros de divulgação científica sobre diversos temas.

Ciência Hoje é uma revista de divulgação científica, que publica resultados de pesquisas feitas no Brasil e no exterior - de todas as áreas do conhecimento científico - para um público amplo e heterogêneo. Os leitores são, em geral, estudantes e professores de ensino médio, universitários e leigos que se interessam por ciência, mas não dominam necessariamente conceitos básicos de todas as áreas. Os textos da revista exigem, portanto, clareza e o máximo de simplicidade, dando ênfase a imagens (ilustrações ou fotos) que facilitem a sua compreensão. ${ }^{3}$

De acordo com o referencial teórico (ditos, já-ditos e não-ditos), foram estabelecidas, a priori, quatro categorias de análise - assunto, justificativa, problematização e ausências - que serão exemplificadas a partir de enunciados dos artigos selecionados de forma a entender como essas categorias são representadas ao levar-se em conta o dialogismo dos enunciados. Neste trabalho, selecionamos, de cada periódico, os dois artigos mais atuais que abordassem a temática do RAV (Quadro 1), de forma que entre os quatro artigos, dois discutem vídeo, um, cinema e um, animação.

Quadro 1: Artigos dos periódicos selecionados para análise.

\begin{tabular}{|c|c|c|c|c|}
\hline PERIÓDICO & ARTIGO & TÍTULO & AUTORIA & $\begin{array}{c}\text { RECURSO } \\
\text { AUDIOVISUAL }\end{array}$ \\
\hline \multirow{2}{*}{$\begin{array}{l}\text { Revista de } \\
\text { Manguinhos }\end{array}$} & A & Mosquitos na Telinha & Ferreira (2013) & vídeo \\
\hline & B & $\begin{array}{c}\text { Precisa-se de Cuidado e } \\
\text { Carinho }\end{array}$ & Marques (2012) & vídeo \\
\hline \multirow{2}{*}{ Ciência Hoje } & $\mathrm{C}$ & $\begin{array}{l}\text { A luz como linguagem no } \\
\text { cinema }\end{array}$ & Santos (2015) & cinema \\
\hline & $\mathrm{D}$ & $\begin{array}{l}\text { A matemática da animação } \\
\text { por computador }\end{array}$ & $\begin{array}{c}\text { Figueiredo, Nehab e } \\
\text { Velho (2013) }\end{array}$ & animação \\
\hline
\end{tabular}

\footnotetext{
${ }^{3}$ Disponível em: <http://www.cienciahoje.org.br/revista/ch>.
} 


\section{RESULTADOS}

Optamos por apresentar os resultados, separadamente, por periódico para, posteriormente, em nossas considerações finais, elencarmos as questões que aproximam ou afastam os enunciados presentes nos artigos, de forma a entender o dialogismo entre eles.

\section{Revista de Manguinhos}

No Quadro 2 encontram-se o resumo dos enunciados dos dois artigos analisados da Revista de Manguinhos para as quatro categorias de análise: assunto, justificativa, problematização e ausências.

Quadro 2: Categorias dos dois artigos da Revista Manguinhos.

\begin{tabular}{|c|c|c|c|c|}
\hline ARTIGO & ASSUNTO & JUSTIFICATIVA & PROBLEMATIZAÇÃo & AUSÊNCIA \\
\hline A & Aedes Aegypti & Ajudar a conhecer & Educação/escolas & $\begin{array}{c}\text { Questões } \\
\text { sociais }\end{array}$ \\
\hline B & Alzheimer & $\begin{array}{c}\text { Conscientizar as } \\
\text { pessoas }\end{array}$ & $\begin{array}{c}\text { Promoção das } \\
\text { informaços }\end{array}$ & $\begin{array}{c}\text { Questões } \\
\text { sociais }\end{array}$ \\
\hline
\end{tabular}

O texto do artigo A compreende duas laudas nas quais há uma introdução e uma descrição do que é tratado nos dez módulos das videoaulas produzidas na Fiocruz para divulgar informações sobre o mosquito da espécie Aedes aegypti, produzido pelo Instituto Oswaldo Cruz (IOC) de Manguinhos. Ele apresenta dois planos enunciativos, duas marcas de subjetividade, um do autor do artigo e outro da idealizadora dos módulos, identificados pelas marcas textuais: o primeiro como argumentador do texto e o segundo por intermédio da estratégia discursiva da citação direta, no uso de aspas. Dessa forma, entende-se que o locutor-autor do artigo articula sua voz em consonância com o que é dito pela criadora dos módulos, num dialogismo de justificação e concordância.

No que diz respeito ao assunto, o enunciado do artigo A, "aborda assuntos variados, incluindo orientações sobre combate aos focos do mosquito, diferenças entre o Aedes Aegypti e o pernilongo doméstico, informações sobre o vírus", e, de certa forma, parece conter a representação de uma conduta a ser seguida por intermédio das orientações dos vídeos. 
Quanto à justificativa, o artigo é endereçado à população em geral, uma vez que anuncia ter o "objetivo de ajudar a população a conhecer um pouco mais sobre o Aedes aegypti, a dengue e seus impactos", entendendo que os vídeos devam ser de conhecimento de todas as pessoas.

$\mathrm{Na}$ problematização, destacam-se as escolas como um dos focos centrais da iniciativa da produção das videoaulas, expondo, dessa forma, esses espaços como um dos lugares carentes de informação: "Nós recebemos muitos pedidos de professores, que solicitam tanto materiais educativos quanto a presença de cientistas no ambiente escolar, como forma de sensibilizar os alunos". No entanto, não é claro o perfil da escola e do professor que faz tal solicitação à instituição.

$\mathrm{Na}$ descrição do vídeo, apesar das videoaulas abordarem os locais e condições de proliferação do mosquito, não há menção às questões sociais que poderiam levar a essa situação, ou como o morador/cidadão poderia criar perspectivas para, de fato, combater o mosquito, uma vez que, dependendo do perfil socioeconômico e cultural, os combates podem variar e, portanto, o conhecimento necessário também. Um exemplo é o encontrado no trecho do artigo:

$O$ vídeo também traz exemplificações de possíveis criadouros em ambiente doméstico e, ainda, como evitá-los, a partir de intervenções práticas na arquitetura de uma residência, como a construção correta do caimento de água em um ralo e como utilizar uma tela para evitar focos do mosquito em canaletas.

Além da questão da terminologia, a ausência de reflexão sobre os aspectos sociais reforça o caráter técnico desse texto de DC, que leva em consideração que professores e alunos são os principais multiplicadores das videoaulas, tal qual explicitado no enunciado "informações capazes de contribuir na rotina tornando-os verdadeiros multiplicadores de conhecimentos". Nesse sentido, o artigo A parece apontar para uma crítica sobre a carência na preparação desses profissionais para abordar problemas mais específicos.

$\mathrm{O}$ artigo $\mathrm{B}$, também composto por duas laudas, trata do vídeo "Alzheimer, mudanças na comunicação e no comportamento", documentário dirigido por Thereza Jessourun, fruto de uma iniciativa que estimula financeiramente a produção de vídeos em saúde pela "VideoSaúde - Distribuidora da Fiocruz, com o apoio da Editora Fiocruz, o selo Fiocruz Vídeo, e tem como objetivo incentivar o trabalho realizado por produtores independentes (pessoas físicas ou jurídicas), a partir de editais de financiamento ou de aquisição". 
A autora desse artigo tem a preocupação de descrever outras obras da diretora do vídeo e esclarecer que ele foi premiado na Mostra Nacional de Vídeos em Saúde. O dialogismo no texto compreende planos enunciativos como o da própria autora do texto, a voz de familiares, dados estatísticos, especialistas (geriatra, psiquiatra) no assunto. Trata-se, portanto, de um vídeo específico, divulgado pelo artigo como ferramenta de informação com a disponibilização de um website para download, endereçando-o aos familiares que enfrentam os problemas decorrentes do diagnóstico de Alzheimer e tendo como maior preocupação apresentar o vídeo como aquele que "reúne informações preciosas para as famílias que recebem um diagnóstico de doença de Alzheimer".

$\mathrm{O}$ artigo tem como justificativa e interesse conscientizar as pessoas sobre essa doença tal como esclarecido pelo enunciado "o documentário conscientiza o público sobre a evolução da doença e sua repercussão, tanto para os pacientes como para seus parentes e amigos". Além disso, ele traz uma ênfase alarmista sobre a questão no Brasil, já que a população de idosos está aumentando, ao indicar que " $O$ objetivo maior do vídeo é chamar a atenção da sociedade e das autoridades para a doença de Alzheimer, que por ser uma enfermidade característica das faixas etárias mais avançadas toma uma proporção muito grande em face do processo de envelhecimento da população brasileira".

No que diz respeito à problematização, o texto do artigo $\mathrm{B}$ parece priorizar a ação de promover a informação para que familiares e profissionais estejam capacitados para enfrentar o problema: "a ampla divulgação de informações sobre Alzheimer se faz cada vez mais necessária, para que familiares e profissionais estejam conscientes e capacitados para lidar com o problema". A educação se dá pelas informações presentes no vídeo, a partir de dados médicos e de experiências pessoais, por intermédio de relatos da associação de parentes e amigos de pessoas acometidas com Alzheimer.

No aspecto das ausências, mais uma vez, algumas questões sociais ficam de fora. Apesar de o artigo abordar a existência de medicamentos para a doença, a matéria não articula questões como custo e programas de governo: "Existem medicamentos que auxiliam no tratamento do paciente com Alzheimer, mas este não deve ser transformado em uma 'pessoa-pílula', adverte, no documentário". Outra dimensão que poderia ser mencionada com mais reflexão são as estimativas da agência internacional da saúde no sentido de entender melhor o aumento de casos dessa doença em países de baixa e média renda. 


\section{Ciência Hoje}

No Quadro 3, apresentamos o resumo dos enunciados dos dois artigos analisados da revista Ciência Hoje para as quatro categorias de análise: assunto, justificativa, problematização e ausências.

Quadro 3: Categorias dos dois artigos da Ciência Hoje.

\begin{tabular}{|c|c|c|c|c|}
\hline ARTIGO & ASSUNTO & JUSTIFICATIVA & PROBLEMATIZAÇÃo & AUSÊNCIA \\
\hline C & Luz & $\begin{array}{c}\text { Elemento narrativo nas } \\
\text { construções fílmicas }\end{array}$ & $\begin{array}{c}\text { Desenvolvimento } \\
\text { humano }\end{array}$ & $\begin{array}{c}\text { Questões } \\
\text { políticas }\end{array}$ \\
\hline D & $\begin{array}{c}\text { Matemática } \\
\text { geométrica }\end{array}$ & $\begin{array}{c}\text { Produção do filme de } \\
\text { animação }\end{array}$ & $\begin{array}{c}\text { Aprendizagem de } \\
\text { conceitos }\end{array}$ & Acessibilidade \\
\hline
\end{tabular}

$\mathrm{O}$ artigo $\mathrm{C}$, intitulado "A luz como linguagem do cinema", é composto por quatro laudas e tem como objetivo a discussão da linguagem do cinema sobre três aspectos: referenciabilidade, ação crítica e transparência cultural. $\mathrm{O}$ autor apresenta a análise de como a luz se tornou elemento narrativo nas construções fílmicas, como no enunciado "O uso e a percepção da luz nas imagens cinematográficas dispõem de elementos estéticos abrangentes o suficiente para que sejam caracterizados como elemento narrativo", e parece fazer uso de um único plano enunciativo.

Pode-se dizer que o texto está endereçado para o público em geral, ao explicar como a luz se tornou comunicação no cinema e na cultura, criando um diálogo com a área da linguagem, comunicação e sociocultural: "coletividades desenvolveram percepções culturais sobre e a partir da luz, as quais são materializadas nas formas de simbolização social, como nas interações que acontecem por meio do uso das linguagens".

No que concerne à problematização, o artigo expõe a luz como determinante para o desenvolvimento do ser humano, principalmente sua capacidade criativa. No enunciado "Com o domínio da luz, de quando e onde iluminar, novos modos de organização das atividades produtivas e das interações sociais foram possíveis", há ênfase na ampliação dos significados como no que é alcançado pela mente humana. Outra característica desse artigo é a abordagem de questões históricas, mesmo sem esclarecer questões políticas que envolvem o cinema e o uso da luz, como exemplificado nos enunciados a seguir: 
Depois, a luz do fogo trouxe a segurança e o calor, protegendo os indivíduos da escuridão e do frio das noites.

Antes de desenvolvida a tecnologia de controle do fogo, a luz solar era a referência luminosa determinante para todas as atividades humanas de coleta de alimentos e organização social.

Como seres culturais, simbolizamos não só a luz, mas todos os elementos do mundo natural por meio de nossas linguagens, que traduzem, interpretam, comunicam, codificam, dão significado e expressam nossas experiências e interações com os fenômenos naturais e culturais.

Por fim, o artigo D, intitulado "A matemática da animação por computador", voltado ao público em geral, refere-se a uma animação por computador. É composto por duas laudas nas quais a principal preocupação parece ser a de explicar a produção da animação por intermédio de computação gráfica. Ele parece incluir apenas um plano enunciativo, embora tenha sido escrito por três autores.

Os enunciados justificam a produção da animação para aplicar conceitos de matemática "Para criar uma cena virtual no computador, precisamos representar matematicamente os objetos que a compõem”. Em relação à problematização, os autores fazem uso de conceitos da geometria para demonstrar a construção das animações por computador, como explicitam os enunciados "Como cada objeto tem uma forma geométrica e uma posição no mundo virtual, usamos o ramo da geometria conhecido como geometria analítica espacial" e "A matemática das aproximações de geometrias curvas por malhas de polígonos existe há mais de 100 anos".

O texto não faz uma reflexão sobre a acessibilidade ao experimento, deixando como sugestão programas gratuitos e modelos de computador para sua replicação, conforme explicitados nos enunciados "Mas teve grande desenvolvimento com o advento de computadores poderosos devido às aplicações em engenharia e computação gráfica" e "Na animação por computador, essas etapas correspondem, respectivamente: i) à construção dos ambientes e personagens; ii) à especificação dos movimentos e da câmera; iii) à síntese das imagens (renderização)".

\section{CONSIDERAÇÕES FINAIS}

Os quatro artigos analisados neste trabalho variaram em termos de vozes e planos enunciativos, tanto no que diz respeito ao dialogismo, ao endereçamento (geral, professores, família), às propostas de uso de RAV e aos silenciamentos identificados (questões sociais e políticas). 
Os artigos da Revista de Manguinhos parecem configurar enunciados que representam aspectos mais prescritivos acerca dos vídeos. Percebe-se também o vídeo como transmissor de um conhecimento prático para melhorar o cotidiano do leitor. No entanto, o cotidiano não é problematizado, sendo considerado o mesmo para a diversidade da população. Os artigos enfatizam, assim, a dimensão informativa dos vídeos e, consequentemente, da DC, corroborando as ideias de Orlandi (2008). Esses RAV de DC parecem, nos artigos da Revista de Manguinhos, servirem para representar e divulgar um conhecimento pré-existente, mas não serem veículos de produção e construção de novos conhecimentos.

Quanto à revista Ciência Hoje, os textos sobre a luz e o cinema e a geometria e a animação parecem, pela produção da imagem e da ação sugerida, exemplificar e construir conceitos sobre conteúdos de ciências (física) e de matemática (geometria) em enunciados que fomentam a informação e a formação. Trata-se da elaboração de estratégias que mostram como o conhecimento científico está presente em elementos comuns do cotidiano dos cidadãos e que podem ser utilizadas para motivar a ampliação desse conhecimento para não-cientistas. Nesses casos, os RAV são elementos presentes no cotidiano e sobre os quais o leitor pode não conhecer o papel da ciência. Esse aspecto difere do que encontramos nos artigos mais atuais sobre RAV na Revista de Manguinhos, já que na Ciência Hoje não se encontrou um discurso elaborado sobre o vídeo como ferramenta de DC, o que pudemos ver na primeira.

Por meio dessa investigação, verificou-se que a vinculação dos RAV com a DC se dá ainda de forma ambígua e difusa. Diferentes concepções sobre essa vinculação foram encontradas nos quatro artigos das duas RDC consideradas, demonstrando não haver nem um consenso no discurso, nem uma homogeneidade na maneira como tais recursos são tratados, já que esse tratamento varia na consideração deles como uma ferramenta de informação ou como um artefato tecnológico de uso comum que se torna objeto de "curiosidade científica".

Como última consideração, indicamos algumas possibilidades futuras para a DC envolvendo RAV, como linhas de financiamento por meio de políticas públicas ou institucionais, como museus e instituições científicas, para fomento da produção de vídeos como forma de despertar o interesse para as atividades que oferecem, ou ainda valorizando a produção de vídeos por produtores independentes que se preocupem em difundir e popularizar a ciência, sobretudo por meio de canais no Youtube. 


\section{AGRADECIMENTO E APOIO}

IFRJ e FAPERJ.

\section{REFERÊNCIAS}

ARROIO, A; GIORDAN, M. O vídeo educativo aspectos da organização do ensino. Química Nova na Escola, n. 24, 2006.

BAKHTIN, M. Estética da criação verbal. São Paulo: Martins Fontes, 2003.

BRAIT, B. Bakhtin, conceitos-chaves. São Paulo: Contexto, 2006.

CARDOSO, S. H. B. Discurso e ensino. Belo Horizonte: Autêntica, 2005.

DI FANTI, M. G.C. A linguagem em Bakhtin: pontos e pespontos. Veredas - Revista de Estudos Linguísticos, v. 7, n. 1 e 2, p.95-111, 2003.

FERREIRA, V. Mosquitos na telinha. Revista de Manguinhos, 27, julho, 2013.

FERREIRA, L. N. A., QUEIROZ, S.L. Textos de divulgação científica no ensino de Ciências: uma revisão. Alexandria. Revista de Educação em Ciência e Tecnologia, v. 5, n. 1, 2012.

FIGUEIREDO, L. H.; NEHAB, D.; VELHO, L. A matemática da animação por computador. Ciência Hoje, n. 305, 2013.

MARCHEZAN, R. C. Diálogo. In: BRAIT, B. (org.). Bakhtin: outros conceitos-chave. São Paulo: Contexto, 2006. p. 115-131.

MARQUES, F. Precisa-se de cuidado e carinho. Revista de Manguinhos, n. 24, 2012.

MARTINS, I. NASCIMENTO, T. G.; ABREU, T. Clonagem na sala de aula: um exemplo do uso didático de um texto de divulgação científica. Investigações em Ensino de Ciências, v. 9, n. 1, 2004.

ORLANDI, E. P. Discurso e Texto. Formulação e circulação dos sentidos. Campinas: Pontes Editores, 2008.

SANTOS, L. C. A luz como linguagem no cinema. Ciência Hoje, n. 328, 2015.

SANTOS, P. C; ARROIO, A. A utilização de recursos audiovisuais no ensino de ciências: tendências nos ENPECs entre 1997 e 2007. In: ENCONTRO NACIONAL DE PESQUISA EM EDUCAÇÃO EM CIÊNCIAS, 7., Florianópolis, 2009. Anais... Associação Brasileira de Pesquisa em Educação em Ciências, 2009.

VYGOTSKY, L. S. Pensamento e Linguagem. São Paulo: Martins Fontes, 2002. 